\title{
Quality of life and psychomotor profile of children with attention deficit hyperactivity disorder (ADHD)
}

\author{
Juliana Barbosa Goulardins', Juliana Cristina Fernandes Bilhar Marques', \\ Erasmo Barbante Casella²
}

\begin{abstract}
The knowledge of psychomotor development of children with attention deficit hyperactivity disorder (ADHD) may help in defining therapeutic approaches in order to minimize losses in their quality of life. The study objectives were to evaluate the quality of life and psychomotor profile of children with ADHD and check your correlation. Fourteen children, from seven to ten years, with ADHD combined type were evaluate using the scales Peds $\mathrm{QL}^{\mathrm{T}}{ }^{\mathrm{M}}$ and Motor Development Scale. Results showed adverse effects of ADHD on quality of life and a deficit in motor skills. Nine participants (64.2\%) were classified in motor development as "Normal Medium", followed by the classification "Normal Low" in four (28.5\%) and "Low" in one subject (7.1\%). We observed a positive correlation between quality of life and psychomotor development of children with ADHD, especially in areas: fine motor and spatial organization with social and psychosocial aspects, gross motor control with the emotional and temporal organization with the emotional, psychosocial and overall quality of life.
\end{abstract}

Key words: quality of life, child development, ADHD.

Qualidade de vida e perfil psicomotor de crianças com transtorno de déficit de atenção e hiperatividade (TDAH)

\section{RESUMO}

O conhecimento sobre desenvolvimento psicomotor das crianças com TDAH pode auxiliar nas propostas terapêuticas, a fim de minimizar os prejuízos em sua qualidade de vida. Os objetivos do estudo foram avaliar a qualidade de vida e o perfil psicomotor de crianças com TDAH e verificar sua correlação. Quatorze crianças, de sete a dez anos, com TDAH do tipo combinado foram avaliadas pelas escalas Peds $L^{\text {TM }}$ e Escala de Desenvolvimento Motor. Os resultados mostraram impactos negativos do TDAH na qualidade de vida e déficit nas habilidades motoras. Nove participantes $(64,2 \%)$ se classificaram com desenvolvimento motor "normal médio", seguidos das classificações "normal baixo" em quatro $(28,5 \%)$ e "inferior" em um indivíduo (7,1\%). Observou-se correlação positiva entre qualidade de vida e o desenvolvimento psicomotor de crianças com TDAH, principalmente em: motricidade fina e organização espacial com os aspectos social e psicossocial, motricidade global com o aspecto emocional e organização temporal com os aspectos emocional, psicossocial e qualidade de vida total

Palavras-chave: qualidade de vida, desenvolvimento infantil, TDAH.

\section{Correspondence \\ Juliana Barbosa Goulardins \\ Rua Fosca 50 / apto 52A \\ 04159-040 São Paulo SP - Brasil \\ E-mail: jugoulardins@yahoo.com.br}

Received 30 November 2010 Received in final form 11 April 2011 Accepted 18 April 2011
The attention deficit hyperactivity disorder (ADHD) is a deficit of self-control development, which displays issues as- sociated to attention, impulse control, and activity levels ${ }^{1}$. In 2007, Polanczyk et al. ${ }^{2}$ in a systematic review estimated the

${ }^{1}$ Physiotherapist Specialist in Physiotherapy Neurofunctional by Irmandade Santa Casa de Misericórdia of São Paulo. Masters in Pediatrics by Faculty of Medicine in the University of São Paulo, São Paulo SP, Brazil; ${ }^{2}$ Physician Assistant of Unit Neuropediatrics in the Child Institute at Clinical Hospital in the University of São Paulo's Faculty of Medicine, São Paulo SP, Brazil. 
global incidence of the disorder of $5.29 \%$ in pediatric population.

These children normally display a lack in academic performance, in social relations, as well as in emotional aspects ${ }^{1}$. They also show disadvantages regarding their relation with their parents, teachers and children of the same age, frequently proceeding to a lack of self-esteem, and a higher risk for depression, anxiety and delinquent behavior $^{3}$.

Klassen et al. ${ }^{4}$ observed that ADHD has a significant impact in multiple realms associated to the quality of life of children and adolescents. In this study, involving the parents and/or caretakers narratives, the children with this disorder show emotional and behavioral problems, in addition to influencing their parents causing emotional distress, interfering in their family activities.

Quality of life is a concept defined by the World Health Organization as the individual perception of one's position in life, regarding to the cultural context, goals, in his/her social context and in the value system he/she is inserted ${ }^{5}$. Thus, it represents the effort to assign some characteristics to the human experience, being as the major factor, the subjective sense of well-being ${ }^{5,6}$.

To children and teenagers, well-being could be associated with the distance between their wishes and hopes, and reality as it actually is. It also reflects their prospecting, to themselves and to others, and it is prone to change, being influenced by everyday events ${ }^{3,4,7}$.

The emotional aspect has strong influence over the intellectual development, being a self-regulated process which implies in making way for the individual to acquire proper independence, enabling him/her to choose and to make decisions ${ }^{8}$.

Besides academic, social and emotional performance matters, children with ADHD were acknowledged as having distinctive and different motor quality, when compared to children that do not have the disorder. It is believed that the major reason for motor difficulty is an inability in planning and carrying out motor tasks 9

Those children demonstrate that they are unable to select a task or their action's overriding object consciously, and not being in charge of their own body, which indicates a disharmony between feeling, thinking and acting ${ }^{10,11}$. The excessive level of activity with unnecessary body movements, impulsiveness, answer anticipation, and inability to wait for an event can cause difficulties in learning and motor disturbance, interfering directly in their academic life, having as a result lower grades at school, and loss of self-esteem ${ }^{12,13}$.

Studies indicate that an ADHD child's psychomotor ability is meaningfully lower than expected. Nearly half of those children show difficulties, but data vary from $30 \%$ to $50 \%{ }^{14}$.
This disorder's impact in society is enormous, taking into account its high financial cost, the parental stress and academic and professional damage ${ }^{15}$. The knowledge about psychomotor development and possible alteration in ADHD children may be of help regarding treatment goals, in order to minimize the impacts on quality of life and guide a new educational and psychosocial development of children with $\mathrm{ADHD}^{16}$.

The objective of the study was to analyze quality of life and the psychomotor profiles of children with ADHD, and also to verify if there was a correlation between both variables.

\section{METHOD}

A cross-sectional study was conducted on patients with ADHD receiving care at the Learning Disorders Ambulatory of the Child Institute at the Hospital das Clínicas of the University of São Paulo Medical School between May and October 2007.

Fourteen children (13 males and one female) aged seven to ten years who met the DSM-IV criteria for ADHD combined subtype, without comorbidities except the oppositional-defiant disorder, participated in the study. All children were taking stimulant medication (methylphenidate). Parents provided written informed consent for their children.

The following exclusion criteria were adopted: children with visual, hearing, heart diseases, rheumatology and orthopedic dysfunctions, as well as neurological diseases and neuropsychiatric disorders.

PEDsQL ${ }^{\mathrm{TM}}$ Scale - Measurement Model for the Pediatric Quality of Life Inventory ${ }^{\mathrm{TM}}$ was chosen for this study for presents a reliable translation into Portuguese and a pediatric self-report module. It was created in order to measure the dimensions of the health core, as determined by The World Health Organization, regarding to the physical, social, emotional and academic functions ${ }^{17}$. It's made up of 23 items (physical capacity: 8 items, social aspect: 5 items, emotional aspect: 5 items, school activity: 5 items), and each item is punctuated according to the frequency in which the child presents difficulties in a particular activity. The results can be interpreted by total score or grouped according to the areas: Psychosocial Health and Physical Ability. The score is determined in absolute value ranging from 0 to 100 , so that the higher the score, the better the quality of life ${ }^{17,18}$.

Motor Development Scale was used to analyzed the psychomotor profile of the children of this study. It was published and validated by Poeta and Rosa Neto ${ }^{12}$, which uses a battery of tests involving fine motor skills, global motor skills, balance and body schema, spatial organization / laterality and temporal organization. The tests include specific tasks for each age group (two to 11 years) 
on each element of the motion. The scale was compiled from other motor tests, backed by classical authors, such as Ozerestski, Brunet and Lezina, Berges and Lezine, Mira-Stambak, Galifret-Granjon, Piaget and Head ${ }^{16}$.

The complexity of the task being performed increases as the individual ages. The participants were evaluated taking into account the test corresponding to their chronological age (CA) on each motor element, and ended the assessment when they did not performed properly the proposed task. The age corresponding to the last test performed correctly by the child is characterized by motor age (MA). Comparing the CA and $\mathrm{MA}$, the motor advancement or delay of the child can be determined.

The scales were applied at the same location, in a single session with approximately 40 minutes. Descriptive results are presented by the average and confidence interval of 95\% (IC95\%). The Shapiro-Wilk Test was employed to check the normality of the data. Subsequently, the test was applied for non-paired samples for variable score comparisons assessed among motor development groups. For the analysis of the data between the quality of life variables and psychomotor development, intraclass correlation coefficient ( $r$ ) was employed, which according to Vincent ${ }^{19}$, is the proper one, less biased correlation than Pearson's for small samples, with a $\mathrm{p}<0.05$ of significance.

\section{RESULTS}

Aspects related to quality of life are presented in a descriptive form in Table 1. In Table 2, we present psychomotor profile data that are divided into motor ages, relating to arithmetic means of the test results that are expressed in months and motor quotients that match the division between motor age and chronological age, multiplied by 100 .

Nine participants (64.2\%) were classified in motor development as "Normal Medium", followed by the classification "Normal Low" in four (28.5\%) and "Low" in one subject (7.1\%).

In Graph, the relationship between quality of life (total score) and motor development (general motor age) of each individual is shown.

In Table 3, we can observe the intraclass correlation coefficients demonstrating the quality of life realms that have direct relation to the psychomotor aspect.

\section{DISCUSSION}

In agreement with other previous research, this study showed that ADHD has a significant impact on these children's multiple quality of life realms, especially psychosocial health, and can compromise their psychomotor development.
Table 1. Data describing the evaluation of Quality of Life (PedsQITM).

\begin{tabular}{lcc}
\hline \multicolumn{3}{c}{ Quality of Life - PedsQI $^{\mathrm{TM}}$} \\
\hline & Average & SD \\
\hline Physical capacity & 79.7 & 13.9 \\
Emotional & 54.3 & 20.5 \\
Social & 67.5 & 26.3 \\
School & 58.9 & 26.3 \\
Psychosocial & 60.2 & 16.7 \\
Total & 67.7 & 14.7 \\
\hline
\end{tabular}

Table 2. Descriptive data assessing the Psychomotor Development (MDS). Chronological age and motor age in months and motor quotients in absolute value.

\begin{tabular}{lcc}
\hline \multicolumn{3}{c}{ Psychomotor profile } \\
\hline & Average & SD \\
\hline Chronological age & 111.4 & 13.6 \\
Motor age & & \\
General motor age & 102.1 & 15.3 \\
Fine motor & 112 & 18.1 \\
Global motor & 114 & 15.4 \\
Balance & 102 & 17.9 \\
Body schema & 75 & 17.2 \\
Spatial organization & 96 & 17.2 \\
Temporal organization & 120 & 22.1 \\
Motor quotients & & \\
Fine motor & 101.5 & 9 \\
Global motor & 104 & 9.9 \\
Balance & 92.1 & 10 \\
Body schema & 67.7 & 11.9 \\
Spatial organization & 87.5 & 12 \\
Temporal organization & 99.5 & 14.7 \\
\hline
\end{tabular}

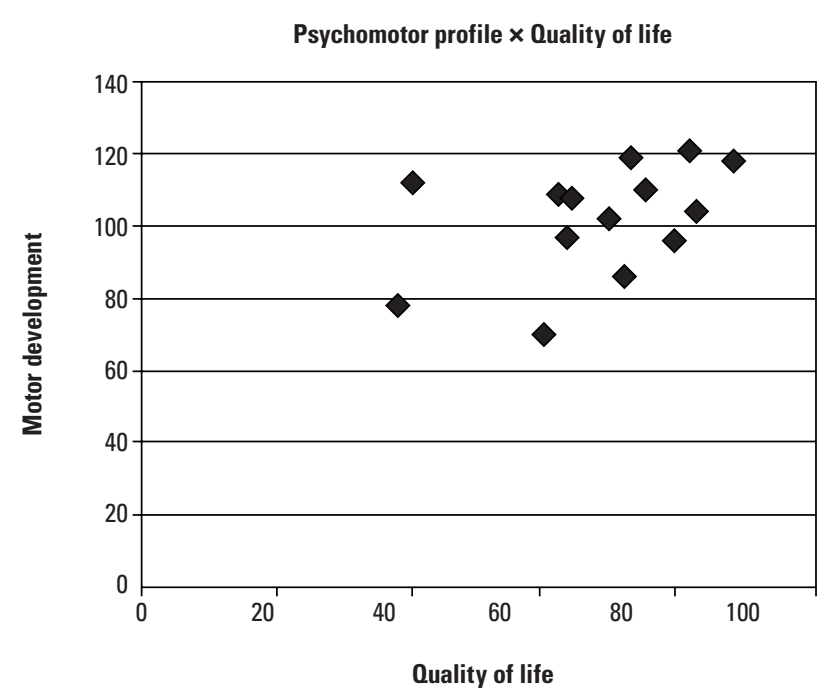

Graph. Distribution of individual values for the general motor age and quality of life total. 
Table 3. Results of static analysis of the correlation between PedsQL $L^{\mathrm{TM}}$ and MDS.

\begin{tabular}{|c|c|c|c|c|c|c|c|c|c|c|c|c|}
\hline \multicolumn{13}{|c|}{ Intraclass correlation coefficient } \\
\hline & \multicolumn{2}{|c|}{ Physical } & \multicolumn{2}{|c|}{ Emotional } & \multicolumn{2}{|c|}{ Social } & \multicolumn{2}{|c|}{ School } & \multicolumn{2}{|c|}{ Psychosocial } & \multicolumn{2}{|c|}{ Total } \\
\hline & $r$ & $\mathrm{R} 2$ & $r$ & $\mathrm{R} 2$ & $r$ & R2 & $r$ & $\mathrm{R} 2$ & $r$ & $\mathrm{R} 2$ & $r$ & $\mathrm{R} 2$ \\
\hline \multicolumn{13}{|l|}{ Motor quotients } \\
\hline Fine motor & 0.39 & 0.15 & 0.10 & 0.01 & 0.65 & $0.42^{*}$ & 0.36 & 0.13 & 0.52 & $0.27^{*}$ & 0.46 & 0.21 \\
\hline Global motor & 0.04 & 0.002 & 0.52 & $0.27^{*}$ & 0.20 & 0.04 & 0.17 & 0.03 & 0.39 & 0.15 & 0.26 & 0.07 \\
\hline Balance & 0.05 & 0.003 & 0.35 & 0.12 & 0.22 & 0.05 & 0.07 & 0.005 & 0.28 & 0.08 & 0.22 & 0.05 \\
\hline Body schema & 0.09 & 0.009 & 0.14 & 0.02 & 0.14 & 0.02 & 0.03 & 0.001 & 0.10 & 0.01 & 0.05 & 0.003 \\
\hline Spatial organization & 0.36 & 0.13 & 0.20 & 0.04 & 0.66 & $0.43^{*}$ & 0.33 & 0.11 & 0.54 & $0.29^{*}$ & 0.50 & 0.25 \\
\hline Temporal organization & 0.48 & 0.23 & 0.56 & $0.31 *$ & 0.49 & 0.24 & 0.36 & 0.13 & 0.61 & $0.37^{*}$ & 0.55 & $0.30^{*}$ \\
\hline
\end{tabular}

The study of Klassen et al. ${ }^{3}$ assessed quality of life of 131 children with ADHD aged between 6 and 17 years, through parents reports making use of the HRQL instrument (Health-Related Quality of Life), and found that these children had the greatest faults on emotional, behavioral, mental health and self-esteem issues, besides the impact on parents emotional health and family dynamics.

The scale PedsQL ${ }^{\mathrm{TM}}$, same instrument used in this study, was chosen by Varni et al. ${ }^{20}$ for evaluation of quality of life in children with ADHD, comparing with kids who had cancer, cerebral palsy and healthy controls. In this study, Varni et al. ${ }^{20}$ observed that children with ADHD have lower scores in psychosocial controls, compared to healthy controls, but there was no significant difference in physical ability.

The present study and the research conducted by Varni et al. ${ }^{20}$ showed similar results, mainly in the following areas: quality of life, with total score of 67 in this study, while Varni et al. ${ }^{20}$ obtained 70 points, and psychosocial health with 60 and 63 respectively. Domains with the lowest score in our study, and, consequently, greater injury to these children were the emotional and academic aspects, which determine a declining total score of the scale (Table 1). These results reaffirm discussions about the compromised self-esteem of bearers of ADHD since observational aspects not related directly with psychosocial health, high-impact factor for quality of life, proved less important when compared with the physical capacity of these children.

In addition to the psychosocial factors, difficulties in executing motor tasks can also reflect on self esteem and quality of life of these children, interfering with school performance, in daily activities and in the formation of the personality. Even with equivalence to normal values in the motor profile, children with ADHD have achieved lower execution levels in skills related to balance body and spatial organization scheme, suggesting the involve- ment of the cerebellar pathways and/or executive functions in ADHD.

For decades the cerebellum was considered with a key role in motor coordination and control of balance, but currently there's an investigation about its role in cognitive functions, such as language, executive and visuo-spatial functions, and behavior. Strengthening the relationship of the cerebellum in ADHD, several studies have shown a lower cerebellar volume in the disorder bearers, compared to the normal controls and also there is reduction of cerebellar activity in tests on operating memory ${ }^{21-24}$.

Currently there is no correlation between studies that determine motor compromise of children with ADHD, which can be pointed to by discrepancy in evaluation methods. Studies related to amendment more prevalent in ADHD describe motor disorder coordination, which is a type of disorder with significant impacts, but little is investigated about motor changes as an integrated symptom of ADHD.

Thompson ${ }^{8}$ reports that the child with ADHD presents schema and body image disorders, so he/she can't connect the location of his/her body in the environment, with the extent and direction of movement. Motion tasks that require precision, directional stability and balance are disturbed.

Rosa Neto and Poeta ${ }^{25}$ studied children with indicators of ADHD through Motor Development Scale. Their results indicated a 23-month negative average motor age, demonstrating a "Normal Low" motor development. The quotients of all areas assessed showed deficits, but the biggest losses were in temporal organization, spatial organization and balance.

Most skill deficits in ADHD may be related to neurological changes found in these individuals, whose main changes found were reductions in volumes: cerebral total of prefrontal cortex of caudate nucleus, globus pallidus, cingulate gyrus, and the cerebellum, mainly in the cere- 
bellar vermis and lower posterior lobe ${ }^{22-26}$. In addition to that, Shaw et al. ${ }^{27}$ identified a delayed maturation of cortical thickness of children with ADHD when compared to healthy controls, especially in frontal regions linked to the ability to inhibit unwanted thoughts and responses of attention, executive control, evaluation of rewards from actions, appropriate and precise motor control to the expected action and working memory.

De Nucci ${ }^{28}$ characterized the psychomotor profile of ten children with ADHD, also using the Motor Development Scale, and found that $40 \%$ of the sample presented "Normal Medium", 40\% "Normal Low" and 20\% "Low". Furthermore, the general motor age was less than the chronological age in $90 \%$ of the cases and the average negative age was approximately 18 months.

By outlining the psychomotor profile, we presented similar data in some indicators, however, in our study the general motor age was negative in nine months, reflecting only the impairment of balance, body and spatial organization schema (Table 2), unlike studies cited, showed that significant delays in all areas were assessed.

Methodologies of studies can explain variations in the results. Our selection criteria were more stringent on comorbidity, so frequent in ADHD, because these can influence on motor performance in a negative way, often acting more importantly than even the disorder itself. Besides that, our age of study was limited according to the association of the scales to correlate them. These factors influenced in the reduced casuistry of our research.

Too many other research studies on motor performance in ADHD were carried out using different scales, such as the Movement Assessment Battery for Children that evaluates handedness mastery, skill in handling the ball and static and dynamic balance. Even though it is a different instrument, the variables assessed demonstrate impairness in general motor performance. Pitcher, Pick and $\mathrm{Hay}^{14}$ evaluated children with clinical diagnosis of $\mathrm{ADHD}$, comparing performance engine in the three subtypes and control group. The researchers noted that all children with ADHD have lack of effectivity when compared to the control group, but by evaluating each subtype, it was evident that the guys predominantly inattentive and combined showed no significant difference when compared to the control group, suggesting a relationship between attention capacity and motor ability, which does not occur with the predominantly hyperactive-impulsive group.

In our research, we noted the absence of studies that indicate the relationship between the physical factors and quality of life or self-esteem of children, for this was the reason we began this work, in which our results could indicate the impact on the quality of life relating directly with impairness in psychomotor development.
Through intraclass correlation test, we see that there is a positive correlation between quality of life and psychomotor development, so that fine motility relates to social and psychosocial aspects, global motor to the emotional aspect, spatial organization with social and psychosocial aspects, and temporal organization with psychosocial and emotional aspects, the effectivity of quality of life (Table 3). These results indicate that the impairment of any of these psychomotor aspects can determine a loss or an improvement in quality of life realms, demonstrating a tendency of a grievance related to the quality of life of individuals with motor impairness (Graph).

Studies suggest that children with ADHD have alteration in psychomotor development and quality of life, separately $3,4,12-17,20,25,28$, we assessed that with this kind of direct correlation between the scales studied, an approach to improving motor development, mainly in the aspects that had significance in this study, can interfere positively on the quality of life of this child.

It is important to note that the impact on quality of life of these children will occur regardless of motor involvement, since the ADHD is a biopsychosocial disorder. However, the improvement of motor performance can develop skills and act on their feelings, improving their self-concept, and actuating on their self-esteem.

Currently children with ADHD have multidisciplinary follow-up with drug treatment, cognitive behavioral therapy, psychotherapy, speech therapies, psychopedagogical treatment, among others, indicating that the child watching is already comprehensive. Adding to these therapies, including psychomotor monitoring, with trained professionals for this purpose, the approach becomes integral, acting positively in their physical, mental and social well-being.

In conclusion, with this study we were able to verify the negative impacts of ADHD in quality of life of children, especially in psychosocial aspects. The outlined psychomotor profile showed delay in motor skills development, primarily in the body structure consciousness, balance and spatial organization.

It suggests that there is a positive correlation between the quality of life and psychomotor development of children with ADHD, although further research and other studies are necessary for the definition of an appropriate psychomotor intervention.

\section{REFERENCES}

1. Barkley RA. Transtorno de déficit de atenção/hiperatividade (TDAH). Manual para diagnóstico e tratamento. Porto Alegre: Artmed, 2008.

2. Polanczyk G, Lima MS, Horta BL, Biederman J, Rohde LA. The worldwide prevalence of ADHD: a systematic review and metaregression analysis. Am J Psychiatry 2007;164:942-948.

3. Klassen AF, Miller A, Fine S. Health-related quality of life in children and adolescents who have a diagnosis of attention-deficit/hyperactivity disorder. Pediatrics 2004;114:541-547. 
4. Klassen AF, Miller A, Fine S. Agreement between parent and child report of quality of life in children with attention-deficit/hyperactivity disorder. Child Care Health Dev 2006;32:397-406.

5. World Health Organization. World Health Organization Constitution. Genebra: World Health Organization, 1947.

6. Barreire SG, Oliveira AO, Kazama W, Kimura M, Santos VLCG. Qualidade de vida de crianças ostomizadas na ótica das crianças e das mães. J Pediatr 2003;79:55-62.

7. Assumpção FB, Kuczynski E, Sprovieri MH, Aranha EMG. Escala de avaliação de qualidade de vida. Arq Neuropsiquiatr 2000;58:119-127.

8. Mattos CA, Thompson R, Mousinho R. A ação terapêutica da psicomotricidade na criança com TDAH. In: Thompson R (Ed). Psicomotricidade clínica. São Paulo: Lovise, 2002:95-107.

9. Pereira HS, Araujo APQ, Mattos P. Transtorno do déficit de atenção e hiperatividade (TDAH): aspectos relacionados à comorbidade com distúrbios da atividade motora. Bras Saude Mater Infant 2005;5:391-402.

10. Antony S, Ribeiro JP. A criança hiperativa: uma visão da abordagem gestáltica. Psic Teor Pesq 2004;20:127-134.

11. Artigas-Pallarés J. Comorbilidad en el trastorno por déficit de atención/hiperactividad.Rev Neurol 2003;36 (Suppl):S68-S78

12. Poeta LS, Rosa Neto F. Estudo epidemiológico dos sintomas do transtorno do déficit de atenção/hiperatividade e transtornos de comportamento em escolares da rede pública de Florianópolis usando a EDAH. Rev Bras Psiquiatr 2004;26:150-155.

13. Kadesjo B, Gillberg C. The comorbidity of ADHD in the general population of swedish school-age children. J Child Psychol Psychiatry 2001;42: 487-492.

14. Pitcher TM, Piek JP, Hay DA. Fine and gross motor ability in males with ADHD. Dev Med Child Neurol 2003;45:8:525-535.

15. Rohde LA, Biederman J, Knijnik MP, et al. Exploring DSM-IV ADHD number of symptoms criterion: preliminary findings in adolescents. Infanto 1998;6: 114-118.

16. Escobar R, Soutullo CA, Hervas A, Gastaminza X, Polavieja P, Gilaberte I. Worse quality of life for children with newly diagnosed attention-deficit/ hyperactivity disorder, compared with asthmatic and healthy children. Pediatrics 2005:116:364-369.
17. Varni JW, Seid M, Kurtin PS. PedsQLTM 4.0: reliability and validity of the Pediatric Quality of Life InventoryTM Version 4.0 Generic Core Scales in healthy and patient populations. Med Care 2001;39:800-812.

18. Klatchoian DA, Len CA, Terreri MT, et al. Qualidade de vida de crianças e adolescentes de São Paulo: confiabilidade e validade da versão brasileira do questionário genérico Pediatric Quality of Life InventoryTM versão 4.0. J Pediatr 2008;84:308-315.

19. Vincent WJ. Statistics in kinesiology. Champaign:Human Kinetics Books 1999.

20. Varni JW, Burwinkle TM. The PedsQL ${ }^{\mathrm{TM}}$ as a patient-reported outcome in children and adolescents with attention-deficit/hyperactivity disorder: a population-based study. Health and Quality of Life Outcomes 2006;4:26.

21. Berquin PC, Giedd JN, Jacobsen LK, et al. Cerebellum in attention-deficit hyperactivity disorder: a morphometric MRI study. Neurology 1998;50: 1087-1093.

22. Giedd JN, Blumenthal J, Molloy E, Castellanos FX. Brain imaging of attention deficit/hyperactivity disorder. Ann N Y Acad Sci 2001;931:33-49.

23. Castellanos FX, Lee PP, Sharp W, et al. Developmental trajectories of brain volume abnormalities in children and adolescents with attention-deficit/ hyperactivity disorder. JAMA 2002;288:1740-1748.

24. Valera EM, Faraone SV, Murrayc KE, Seidman LJ. Meta-analysis of structural imaging findings in attention-deficit/hyperactivity disorder. Biol Psychiatry 2007;6:1361-1369.

25. Poeta LS, Rosa Neto F. Evaluación motora en escolares con indicadores del trastorno por déficit de atención/hiperactividad. Rev Neurol 2007;44: 146-149.

26. Seidman LJ, Valera EM, Makris N, et al. Dorsolateral prefrontal and anterior cingulate cortex volumetric abnormalities in adults with attention-deficit/hyperactivity disorder identified by magnetic resonance imaging. Biol Psychiatry 2006;60:1071-1080.

27. Shaw P, Eckstrand K, Sharp W, et al. Attention-deficit/hyperactivity disorder is characterized by a delay in cortical maturation. PNAS 2007;104: 19649-19654.

28. De Nucci FP. Caracterização do perfil psicomotor de crianças com o transtorno de déficit de atenção e hiperatividade. Tese de Mestrado: Puc-Campinas, 2007 